RESEARCH ARTICLE

\title{
Selection of Cells for Parkinson's Disease Cell-Therapy
}

\section{Ashok Chakraborty and Anil Diwan}

Allexcel, Inc, 1 Controls Drive, Shelton, USA

*Corresponding author: Ashok Chakraborty, PhD, Chief Scientist, AllExcel, Inc, 135 Wood Street, Ste. 200, West Haven, CT 06516, USA, Tel: 203-907-0237, Fax: 203-764-2037

\begin{abstract}
Availability of DOPA in situ and thereafter Dopamine (DA) is the main therapeutic approach to treat the Parkinson's Disease (PD). Human neural stem cells (hNSCs), a good source of DA synthesis and release, have long been demonstrated to be a promising candidate for treating PD. However limited cell sourcing and low-growth rate are major concern of its applicability. Different types of other stem cells or reprogrammed somatic cells, including induced pluripotent stem cells (iPSCs), holds tremendous potentiality for DA synthesis and the treatment of Parkinson's disease (PD). However, several issues like ethical, tumor formation, genetic instability, are undermining their therapeutic application. Further the processes are laborious, time-consuming, and not cost-effective. Here, we compare the potentiality and applicability of using another DOPA-forming, neural crest originated cells, Melanocytes with hNSCs for the possible treatment of PD patients.
\end{abstract}

\section{Abbreviations}

BSA: Bovine Serum Albumin; DA: Dopamine; L-DOPA: L-3,4-Dihydroxy Phenyl Alanine; DAPI:4',6-diamidino-2-phenylindole; DPBS: $\mathrm{Ca}^{++} / \mathrm{Mg}^{++}$-Free Phosphate Buffered Saline; db-cAMP: Dibutyryl cAMP; DAT: Dopamine Transporter; DPAC: DOPAC/3,4-Dihydroxyphenylacetic acid; ELISA: Enzyme-linked immunosorbent assay; FBS: Heat Inactivated Bovine Serum; FITC: Fluorescein Isothiocyanate/Fluorescein; HPLC: High-performance liquid chromatography; IBMX: Isobutyl Methyl Xanthine; MAO-B: Monoamine Oxidase-B; MCLts: Lightly Pigmented Human Primary Melanocytes; $\beta-\mathrm{MSH}$ : Beta Melanocyte Stimulating Hormone; hNSCs: Normal Human Primary Neural Stem Cells; PFA: Paraformaldehyde; PD: Parkinson's Disease; TRP1: Tyrosinase-Related Protein-1; TRP2: Tyrosinase-Related Protein-2/Dopachrome Tautomerase (DT); TH: Tyrosine Hydroxylase

\section{Introduction}

Parkinson disease (PD) as one of the most common neurodegenerative diseases where dopaminergic neurons dies in substantia nigra (SN) of the midbrain and thereby cause marked depletion of Dopamine [1]. To date, PD is still considered to be incurable. Treatment with Levodopa, a precursor of Dopamine significantly remits the symptoms [2], but it is still considered as a palliative treatment. Further, long term uses of Levodopa may cause neural tube defects, Dyskinesia, etc [3].

Cell replacement therapy for PD with dopaminergic (DA) neurons, is considered to be the most promising candidate for restoring nigrostriatal DA transmission [4]. Embryonic stem cells (ESCs) although have been shown to be successfully induced to differentiate into DA neurons in vitro [5-7], many problems like propensity to form teratomas and also ethical issues, limit their uses clinically $[8,9]$. Further, due to a safety concern, gene-transfected cells including induced pluripotent cells (iPSCs) with over expression of DA neurons are not a good choice either $[10,11]$.

Midbrain-derived hNSCs may be more intended to differentiate into DA neurons, however, clinical application has been hindered due to the lack of sufficient midbrain tissues. In addition, midbrain-derived hNSCs lose their proliferative property and multipotency for differentiation in long term cultures [8]. Human neural stem cells (hNSCs) isolated from fetal forebrains can be expanded in cultures for more than a year without losing their multipotency to differentiate into neurons and glial cells [8]. However, forebrain-derived hNSCs appear to hardly differentiate into functional DA neurons, lacking the capacity to release dopamine, compared to midbrain-derived hNSCs, which limited their therapeutic application in PD.

Since the issue is to supply Dopamine in the SN region in PD patients, implantation of melanocytes was another thought. The melanocyte is a neural crest orig-

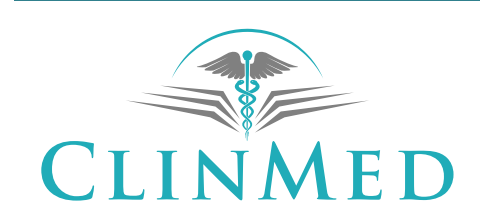

INTERNATIONAL LIBRARY

Citation: Chakraborty A, Diwan A (2019) Selection of Cells for Parkinson's Disease Cell-Therapy. Int J Stem Cell Res Ther 6:063. doi.org/10.23937/2469-570X/1410063

Accepted: November 23, 2019: Published: November 25, 2019

Copyright: (c) 2019 Chakraborty A, et al. This is an open-access article distributed under the terms of the Creative Commons Attribution License, which permits unrestricted use, distribution, and reproduction in any medium, provided the original author and source are credited. 
inated cell and specific for melanin synthesis in the skin from Tyrosine. Tyrosine, a rate-limiting enzyme (EC 1.14.18.1; aminophenol monooxygenase) present in the melanocytes, oxidizes Tyrosine to DOPA and thereafter to melanin in the skin [12].

In the brain, Tyrosine Hydroxylase (EC 1.14.16.2), a rate-limiting enzyme for dopamine (DA) synthesis, can catalyze the conversion of L-tyrosine to L-3,4-dihydroxyphenylalanine (L-DOPA) and thereafter to DA) [13]. Some studies have shown that induced expression of Tyrosinase into Tyrosine Hydroxylase (TH) null mice can reverse the PD symptoms in them [14,15].

The aim of the present study was to investigate the efficacy and potentiality of using the transplantable cells, Melanocytes vs. hNSC, for PD patients based on their fate and behavior under the influence of different environmental conditions including an ideal cell-extracellular matrix interaction, intracellular molecular mediators, growth factors, etc.

\section{Materials and Methods}

\section{Culture of hNSCs (Human Neural Stem Cells)}

hNSCs (H9) derived from adult normal human of female origin were purchased from ThermoFisher (Rockford, IL, USA). The growth and maintenance of undifferentiated hNSCs were conducted with human neural stem cell growth medium supplemented with human neural stem cell growth factors (GS2) and antibiotics (GS1) from Cell Applications (San Diego, CA, USA). In brief, hNSCs were cultured in 6-well tissue culture plates pre-coated with cell-matrix gel (ATCC, Manassas, VA) containing $5 \mathrm{ml}$ complete growth medium at $37^{\circ} \mathrm{C}$ in a $5 \% \mathrm{CO}_{2}$ humidified incubation chamber.

Sub-culturing and passaging of the hNSC spheres were done by mechanical dissociation using Accutase (ATCC, Manassas, VA) into single cells. Single cells $(1 \times$ $\left.10^{6}\right)$ were then plated in the 6-well tissues culture plates coated with Matrix gel (ATCC, Manassas, VA) in $4 \mathrm{ml}$ complete culture medium.

\section{Induction of dopaminergic differentiation of $\mathrm{hN}$ - SCs}

hNSCs, were dissociated with Accutase into single cells and were plated on 6-well plate coated with Cell-Matrix gel in $1 \mathrm{ml}$ complete culture medium supplemented with $1 \%$ heat inactivated fetal bovine serum (FBS) for overnight. Next day, the medium was removed and the fresh medium $(1 \mathrm{~mL})$ with or without differentiation reagents (Cell Applications, San Diego, CA, USA) were added, and incubated for overnight. On the following day, the medium and the cells were collected for determination of DA synthesis by normal and differentiated hNSCs.

\section{Culture of normal human melanocytes}

Normal human adult melanocytes (lightly pig- mented) from male origin were purchased from ATCC, Manassas, VA (Cat\# PCS-200-012), and cultured in dermal growth media containing growth factors, rh-insulin, ascorbic acid, L-glutamine, epinephrine, $\mathrm{CaCl}_{2}$, peptide growth factor, M8 supplements, and antibiotics (ATCC, Manassas, VA, Cat\# PCS-200-042).

Melanocytes are not contact inhibited; however, they will proliferate best if the cells are passaged prior to $100 \%$ confluence. Melanocytes from lightly pigmented tissue should reach $90 \%$ confluence in 7 to 9 days. Passaging of normal melanocytes were done using $0.25 \%$ Trypsin-EDTA and the Trypsin neutralizing solution (ATCC, Manassas, VA).

\section{Induction of melanocyte differentiation}

Differentiation of melanocytes were done using a growth media containing cholera toxin $10 \mathrm{nM}, \beta-\mathrm{MSH}$ 0.01-100 nM, db-cAMP, $10 \mu \mathrm{M}$, and IBMX, $100 \mu \mathrm{M}$ [16].

\section{Immunocytochemistry}

Cells were fixed in $4 \%$ paraformaldehyde (PFA) in $\mathrm{Ca}^{++} / \mathrm{Mg}^{++}$free phosphate buffered saline (DPBS) for $15 \mathrm{~min}$ at room temperature (RT). The cells were incubated with $1 \mathrm{~mL}$ of permeabilization buffer $(0.2 \%$ Triton-X100 plus $0.01 \%$ Tween 20 in PBS) for 40 mins at room temperature, and then incubated with $1 \mathrm{~mL}$ of blocking buffer (5\% BSA and $0.05 \%$ Tween 20 in PBS) for 30 mins. Washed three times with DPBS, followed by overnight incubation with primary antibodies diluted $(1: 1000)$ in PBS containing $5 \%$ BSA, $0.1 \%$ Triton $\mathrm{X}-100$ at $4{ }^{\circ} \mathrm{C}$ in a humidified chamber. On the second day, the cells were washed three times with PBS and incubated for $1 \mathrm{~h}$ at room temperature in the dark with secondary antibodies diluted in PBS (1:5000). All reagents were procured from Sigma-Aldrich (Allentown, PA, USA). After washing three times with DPBS, the cells were cover slipped with medium for fluorescence with DAPI (300 nM, Life Technologies, Carisabad, CA, USA). The magnification of objectives was 20X and total magnification were X200 and viewed by fluorescence microscopy (Zeiss Axio Observer, German).

For hNSCs, the primary antibodies used were: mouse monoclonal Nestin (10C2), 1:1000 (ThermoFisher, Rockford, IL, USA), a Neuron specific mouse monoclonal antibody anti- $\beta$-tubulin III, 1:1000 (Tuj-1, Novus Biologicals, Littleton, CO, USA).The secondary antibody used in these experiments was: anti-mouse FITC, 1:2000 (Novus Biologicals, Littleton, CO, USA).

For melanocytes, the primary antibodies used were: rabbit anti-tyrosinase, 1:1000 (ThermoFisher Scientific, Rockford, IL, USA) and rabbit anti-TRP1, 1:1000 (Novus Biologicals, Littleton, CO, USA). The secondary antibodies used in these experiments were: anti-rabbit Rhodamine, 1:5000 (ThermoFisher, Rockford, IL). 


\section{Proliferation assay}

Proliferation of cells was detected using the Cell-Titer-Glo Luminescent Cell Viability Assay kit (Promega, Madison, WI). For in vitro growth assays, cells $\left(1 \times 10^{3}\right)$ well were plated in 96-well plates and on the next day 0 day reading followed by every alternate day cell growth was measured using the Cell-Titer-Glo-kit until for 6 days. Luminescence was read using the BioTek plate reader [17]. Results were expressed as percentage of vehicle-control cells. Results presented are mean \pm SD from three separate experiments done in triplicate.

\section{Melanin assay}

The colors of cell pellets were evaluated visually, and pellets of $10^{6}$ cells were solubilized by boiling in $1.0 \mathrm{M}$ $\mathrm{NaOH}$ for $10 \mathrm{~min}$. Spectrophotometric analysis of melanin content was done at $400 \mathrm{~nm}$ absorbance, as described previously [18].

\section{Tyrosinase activity assay}

Cell pellets were lysed in $0.1 \mathrm{M}$ sodium phosphate buffer $(\mathrm{pH}$ 6.8) containing $0.5 \%$ Triton $\mathrm{X}-100$, I mM phenylmethylsulfonyl fluoride, $10 \mathrm{pg} / \mathrm{ml}$ aprotinin, and $10 \mathrm{pg} / \mathrm{ml}$ leupeptin. A reaction mixture containing either the enzyme preparation to be measured (0.1 $\mathrm{mg}$ protein cell extract in a total volume of 0.2 $\mathrm{ml}$ sodium phosphate buffer $0.1 \mathrm{M}, \mathrm{pH} 6.8$ ) or the appropriate buffer blank, and L-DOPA $(0.75 \mathrm{mg} / \mathrm{ml})$ in sodium phosphate buffer $(0.1 \mathrm{M}, \mathrm{pH} 6.8)$ was adjusted to $0.2 \mathrm{ml}$ with $100 \mathrm{mM}$ sodium phosphate, $\mathrm{pH} 7.0$, in a plastic multi well plate.

The reaction mixtures with appropriate controls were incubated at $37{ }^{\circ} \mathrm{C}$ and the absorbance was recorded with a spectrophotometer at $400 \mathrm{~nm}$ for periods up to $4 \mathrm{~h}$. DOPA-melanin has been shown to absorb light at these wavelengths [19]. An increase in absorbance over that seen in blank tubes was defined as specific DOPA-Oxidase activity [20].

\section{DOPachrome tautomerase (DT/TRP2) assay}

Spectrophotometric assay of DT activity was carried out using DOPA chrome as a substrate [21]. DOPA chrome was synthesized by mixing ice-cold L-DOPA $(0.75 \mathrm{mg} / \mathrm{ml})$ in sodium phosphate buffer $(0.1 \mathrm{M}, \mathrm{pH} 6.8)$ with solid $\mathrm{Ag}_{2} \mathrm{O}$ (30 mg Ag $\mathrm{O}: 1 \mathrm{mg}$ L-DOPA) for about1 min and then filtering the mixture twice through Gelman Acrodisc Disposable Filters (number 4192, 0.2 pm diameter pore). The standard assay consisted of $0.1 \mathrm{ml}$ red DOPAchrome solution and $0.1 \mathrm{mg}$ protein cell extract in a total volume of $0.2 \mathrm{ml}$ sodium phosphate buffer $(0.1 \mathrm{M}, \mathrm{pH}$ 6.8). The disappearance of absorption at $475 \mathrm{~nm}$ was noted with time. Phenylthiourea $(0.1 \mathrm{mM})$ was included in DT assays to inhibit endogenous tyrosinase, which can interfere with the assay.

\section{Dopamine level by ELISA}

Dopamine release was quantified using ELISA kits
(Eagle Bioscience, Nashua, NH; Cat\# DOP31-K01). All samples were stabilized immediately with orthophosphoric acid $(7.5 \%) /$ metabisulfite $(0.22 \mathrm{mg} / \mathrm{ml})$ and stored at $-80^{\circ} \mathrm{C}$ before analysis. Dopamine extraction, acylation, and enzyme immunoassay were performed according to the manufacturer's instructions. Every sample and standard was performed in duplicate. Absorbance was read using a microplate reader set to $450 \mathrm{~nm}$ and a reference wavelength set between 620 and $650 \mathrm{~nm}$. Data were from three independent experiments.

\section{Tyrosine Hydroxylase (TH) assay by ELISA}

To confirm quantitatively the dopaminergic differentiated hNSCs, the tyrosine hydroxylase enzyme-link immunosorbent assay (TH-ELISA) was performed [22]. Total protein extracted from cells, undifferentiated hNSCs and in presence of differentiated media, were prepared using RIPA lysis buffer. Protein concentrations were determined by the Bradford method (Sigma-Aldrich), using BSA as the standard (Thermo Scientific). After verifying the final protein concentrations, the same concentration of protein was used in all the samples. All samples were used to measure the levels of $\mathrm{TH}$, according to the Kit manufacturer's protocol (USCNK Life Science Inc., Wuhan, China).

\section{Dopamine Transporter (DAT) assay by ELISA}

Human Dopamine Transporter (DAT) Elisa kit were obtained from Biomatik Corp (Cambridge, ON; Cat\# EKU03787). This ELISA kit uses Sandwich-ELISA as the method. The micro ELISA plate provided in this kit has been pre-coated with an antibody specific to human DAT. Standards or samples are added to the appropriate micro ELISA plate wells and combined with the specific antibody. Then a biotinylated detection antibody specific for human DAT and Avidin-Horseradish Peroxidase (HRP) conjugate are added to each micro plate well successively and incubated. Free components are washed away. The substrate solution is added to each well. Only those wells that contain human DAT, biotinylated detection antibody and Avidin-HRP conjugate will appear blue in color. The enzyme-substrate reaction is terminated by adding Stop Solution and the color turns yellow. The optical density (OD) is measured spectrophotometrically at a wavelength of $450 \mathrm{~nm}$. The OD value is proportional to the concentration of human DAT. The concentration of human DAT in samples can be calculated by comparing the OD of the samples to the standard curve. The concentrations calculated from the standard curve were multiplied by the dilution factor.

\section{MAO-B (Monoamine oxidase-B) activity assay}

Mao-B activity assay was done using MAO-Glo assay Kit, Promega (Madison, WI, Cat\# V1401) [23]. In brief, the assay was performed by incubating the cell homog- 
enate, the MAO enzyme source with a luminogenic MAO substrate (4S-4, 5-dihydro-2-(6-hydroxybenzothiazolyl)-4thiazole-carboxylic acid, supplied with the kit). Upon reaction with $\mathrm{MAO}$, the derivative is converted into Luciferin, which in turn reacts with Luciferase to produce light. The amount light produced is proportional to the activity of MAO-B. After the MAO-B reaction has been performed, the reconstituted Luciferin detection reagent is added. The reagent simultaneously stops the MAO reaction and initiates a stable glow-type luminescent signal which is detected by a Bio-Tek Luminometer.

\section{DOPAC (3,4-Dihydroxyphenylacetic acid) assay by HPLC}

A fast and simple isocratic HPLC method for the determination of DOPAC was adopted [24]. In brief, a gradient method was developed to separate DOPAC from Dopamine (DA) and used to determine the DOPAC levels present in the samples using the standard curve. The standard curve was created earlier with LC/UV response at $280 \mathrm{~nm}$. The analytes were separated on a Onyx ${ }^{\mathrm{TM}}$ Monolithic C18, LC Column 100 $\times 4.6 \mathrm{~mm}$ (Phenomenex, Torrance, CA). LC solvents included, Solvent A: $10 \mathrm{mM}$ aqueous ammonium formate containing $0.15 \%$ of formic acid, and Solvent B: Acetonitrile/10 $\mathrm{mM}$ aqueous ammonium formate
(90:10; v/v) and $0.15 \%$ formic acid. Compounds were separated holding the Solvent $A$ isocratically for 2 minutes on the LC column, ramping to $77 \%$ in $5 \mathrm{~min}$ utes. Solvent B was then quickly brought to $100 \%$ within $1 \mathrm{~min}$, and column was held isocratically at $100 \%$ Solvent B for 5 mins. Column was then brought to initial conditions within $1 \mathrm{~min}$, and was allowed to equilibrate at the initial conditions for 8 mins with a total run time of 22 mins. The fluorescence measurements were carried out at $320 \mathrm{~nm}$ with excitation at $279 \mathrm{~nm}$. The calibration curve for DOPAC was linear up to about $2.5 \mu \mathrm{g} / \mathrm{ml}$ with a coefficient of determination of 0.9995 and with a lower limit of quantification of $0.031 \mu \mathrm{g} / \mathrm{ml}$.

\section{Protein Determinations}

Protein content was measured using the Bio-Rad Protein Assay Kit (Bio-Rad, Richmond, CA) with bovine serum albumin as the standard.

\section{Statistical Analysis}

The $t$-test and one-way analysis of variance were used for statistically analyzing the data. All values are expressed as the mean \pm SD. $P$ values $<0.05$ were considered significant. Results are representative of at least three experiments.
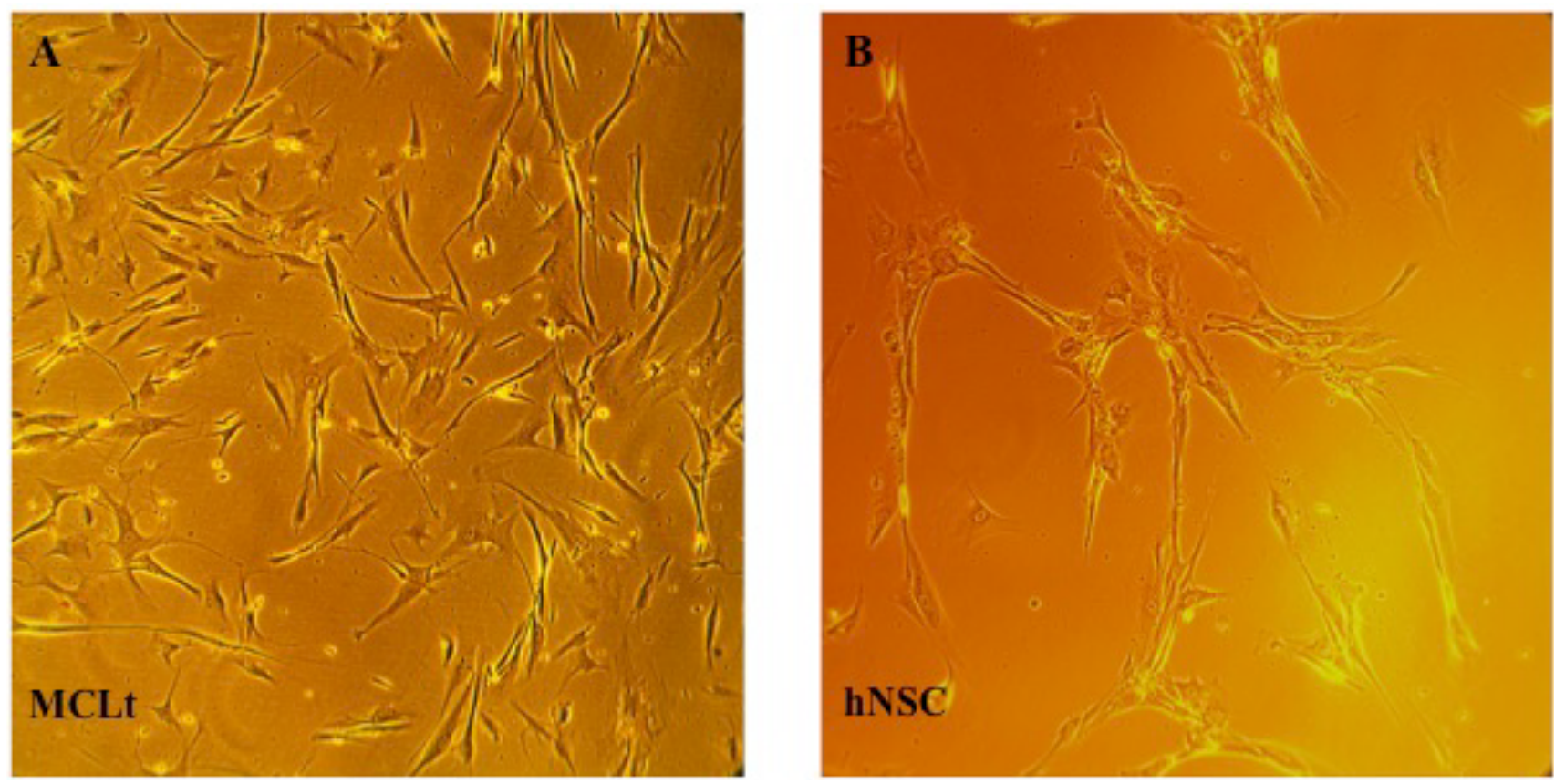

Figure 1: Cells used in this study were cultured in their preferred condition.

A) MCLt: (Normal human adult melanocytes, lightly pigmented, from male origin were purchased from ATCC, Manassas, VA, Cat\# PCS-200-012). Cultured in tissue culture plate with cultured in dermal growth media containing growth factors, rh-insulin, ascorbic acid, L-glutamine, epinephrine, $\mathrm{CaCl}_{2}$, peptide growth factor, $\mathrm{M} 8$ supplements, and antibiotics (Cat\# PCS-200-042, ATCC, Manassas, VA ); B) hNSCs (H9): Adult normal human neural stem cells of female origin were purchased from ThermoFisher (Cat\#780020, Rockford, IL, USA). The growth and maintenance of hNSCs were conducted with human neural stem cell growth medium supplemented with human neural stem cell growth factors (GS2) and antibiotics (GS1) from Cell Applications (Cat\#813-250, San Diego, CA, USA). For culturing hNSCs, tissue culture plates were pre-coated with cell-matrix gel (Cat\#ACS 3035, ATCC, Manassas, VA).

The magnification of objectives was $20 \mathrm{X}$ and total magnification were $200 \mathrm{X}$. 

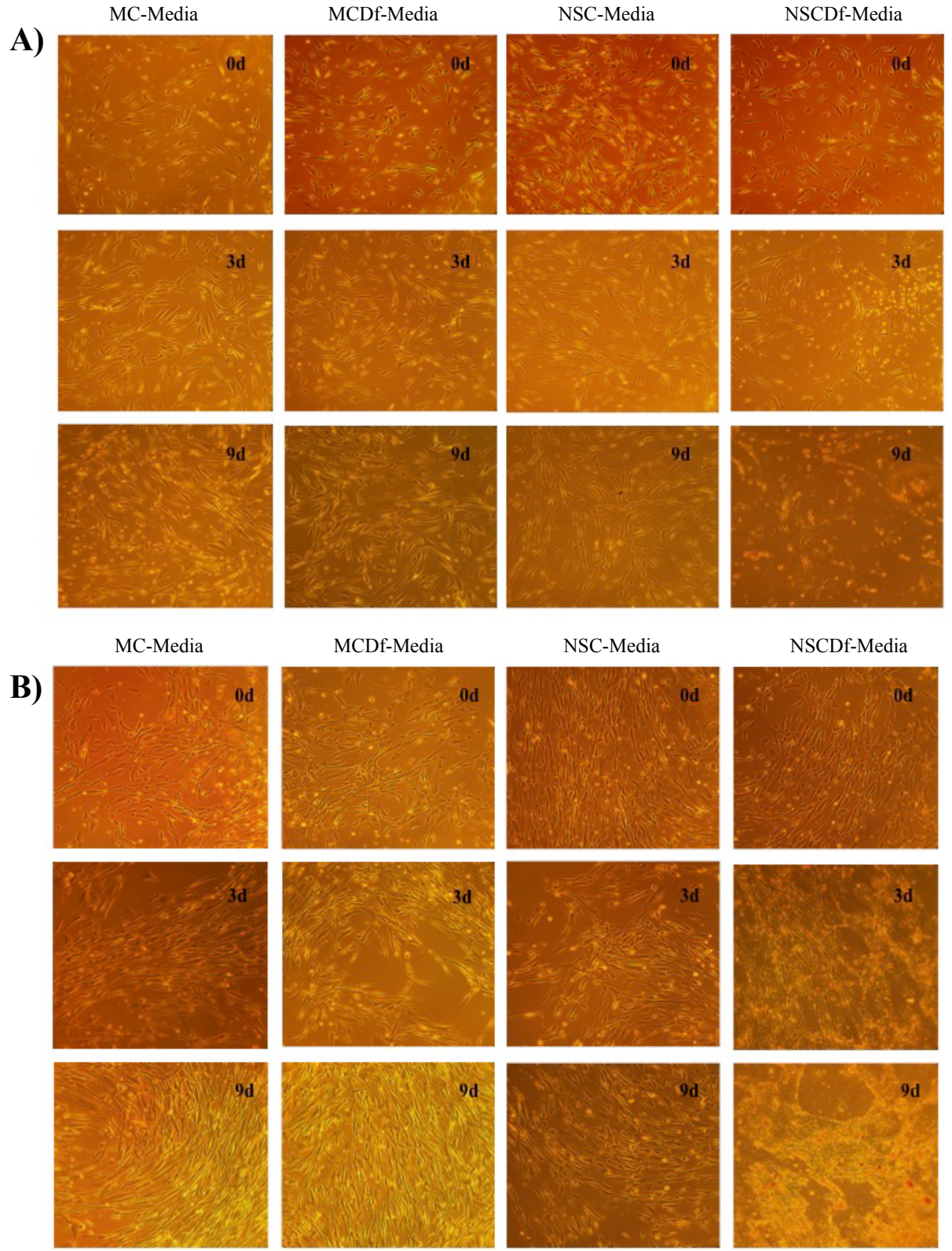

C)
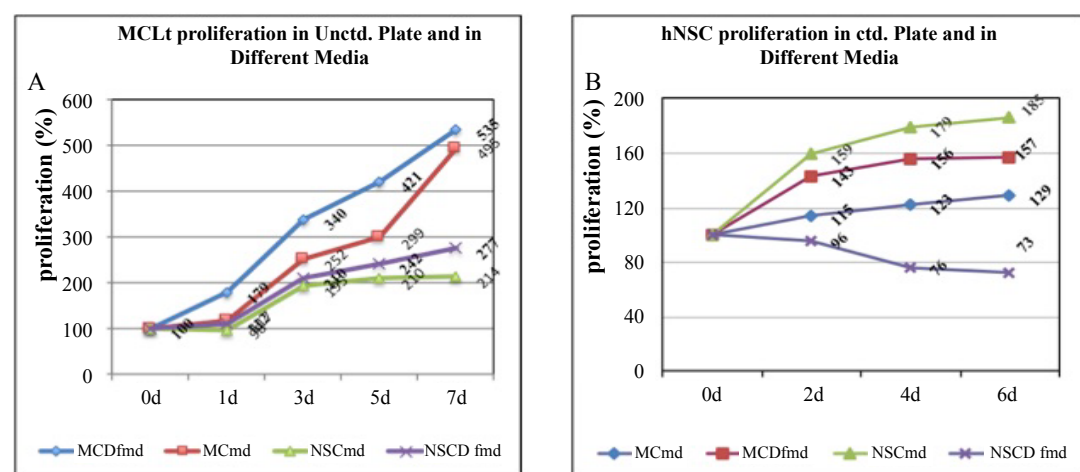

Figure 2: A) Growth and Morphology of MCLt Cells in Different Media. MCLt cells were grown in different media as described in the Materials and Method section. Photographs are taken by Axiovert-100 Microscope (Zeiss, German) in different indicated days. Media preference by MCLts, as shown in the Photographs, are: Mcmed > MCDfmed > NSCmed, but doesn't grow in NSC-Dfmed. The magnification of objectives was 20X and total magnification were 200X.; B) Growth and Morphology of hNSCs in Different Media. hNSCs were grown in different media as described in the Materials and Method section. Photographs are taken by Axiovert-100 Microscope (Zeiss, German) in different indicated days. Media preference by hNSCs, as shown in the Photographs, are: NSCmed > MCmed > MCDfmed > NSC-Dfmed. The magnification of objectives was 20X and total magnification were 200X.. C) Growth of MCLt and hNSC Cells in Different Media: Cell-Glo Proliferation assay. MCLts (Normal Human melanocytes from male origin) and hNSCs (Normal human neural stem cells from female origin) were grown in different media as described in the Materials and Method section. Cell Glo assay for proliferation were done on the respective days and values expressed as $\%$ of 0 day control. Data are from a representative experiment done in triplicate. Percentage or error is all within $10 \%$. 


\section{Results}

\section{Preferred growth conditions and morphology of MCLts and hNSCs (Figure 1)}

MCLts (lightly pigmented normal human adult melanocytes from male origin) were cultured with dermal growth media containing growth factors, rh-insulin, ascorbic acid, L-glutamine, epinephrine, $\mathrm{CaCl}_{2}$, peptide growth factor, M8 supplements, and antibiotics as described in the Materials and methods section (Figure 1A).

hNSCs (H9), adult normal human neural stem cells of female origin were purchased from ThermoFisher, and the growth and maintenance of these cells were conducted with human neural stem cell growth medium supplemented with human neural stem cell growth factors (GS2) and antibiotics (GS1) from Cell Applications (San Diego, CA, USA). For culturing hNSCs, tissue culture plates were pre-coated with cell-matrix gel (Figure 1B).

MCLt cells were grown in different media, like melanocyte growth media (MCmed), melanocyte differentiation media (MCDfmed), hNSC growth media (NSCmed), and hNSC differentiation media (NSCDfmed). Photographs of the morphology were taken by Axiovert-100
Microscope (Zeiss, German) in different indicated days. The magnification of objectives was 20X and total magnification was X200. As it can be noticed from the (Figure $2 A$ ), media preferences of MCLts are: Mcmed $>$ MCDfmed $>$ NSCmed. MCLt cells don't grow well in NSCmed or NSC-Dfmed.

hNSCs, whereas, grow only in NSC-specific media (NSCmed), like human neural stem cell growth medium supplemented with human neural stem cell growth factors (GS2) and antibiotics (GS1) (Cell Applications), but do not grow well in any other media like, MCmed, MCDfmed, and NSCDfmed. Media Preferences of hNSCs are like: NSCmed > MCDfmed > MCmed.

Proliferation rate of MCLts and hNSCs in different media were also documented by Cell-Glow assay (Figure $2 \mathrm{C}$ ), and the results reciprocate the morphology (Figure $2 \mathrm{~A}$ and Figure 2B).

\section{Influence of cell matrix gel pre-coated plate on growth and morphology of MCLts and hNSCs} (Figure 3)

Both the cell types, MCLts and hNSCs, were cultured in 6-well tissue culture plate uncoated (unctd) or pre-coated (ctd) with cell-matrix gel (ATCC, Manas-
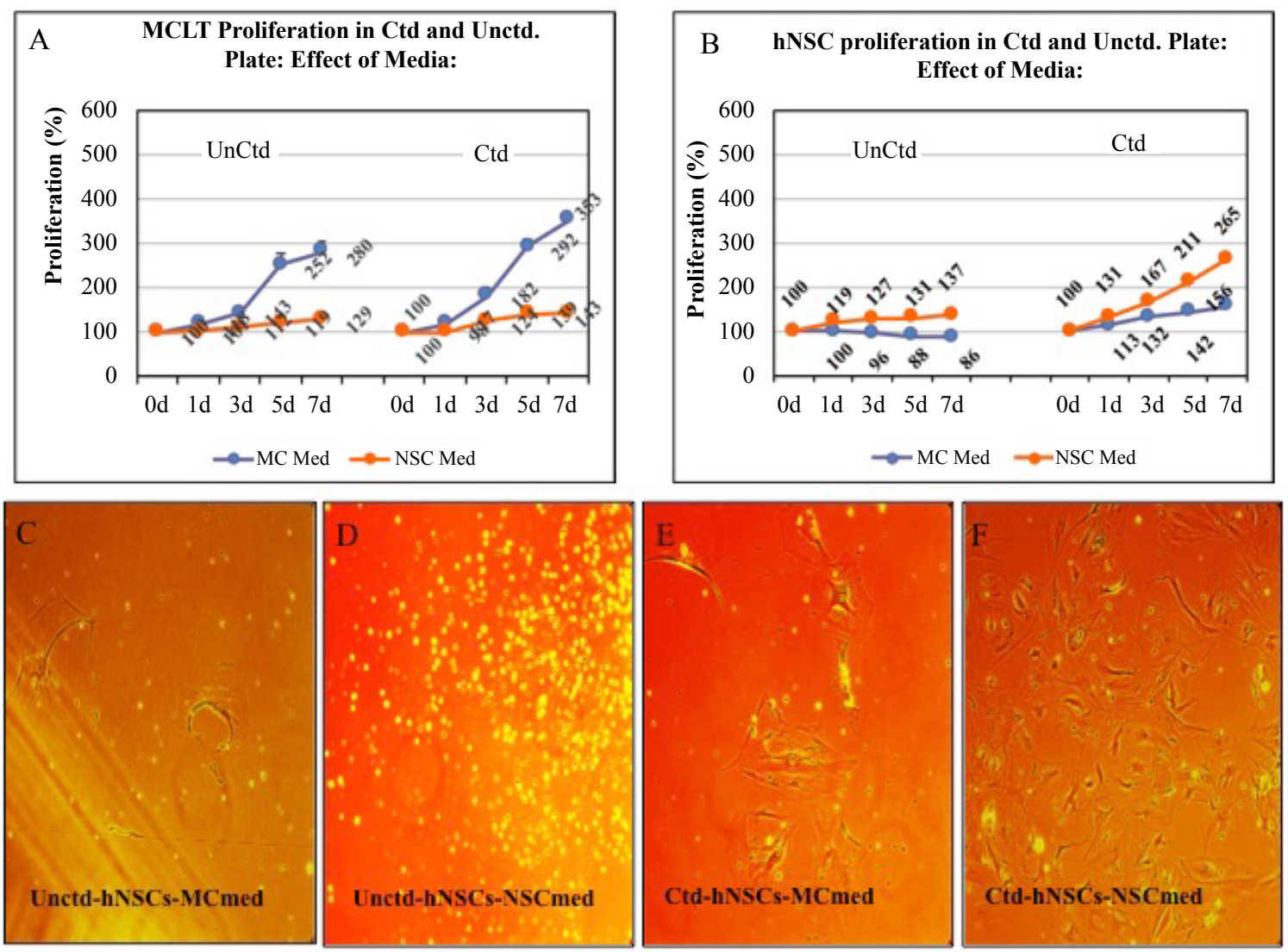

Figure 3: Growth and Morphology of MCLts and hNSCs in Different Media and Conditions. MCLts (Normal Human melanocytes from male origin) and hNSCs (Normal human neural stem cells from female origin) were grown in different media and in different tissue culture plates (Gel coated or uncoated) as described in the Materials and Method section. Cell-Glo assay for proliferation of the cells were done on the respective days and the values expressed as $\%$ of 0 day control. Data are from a representative experiment done in triplicate. Percentage of error are all within $10 \%$.

Photographs (C-F) of the cell morphology were taken by Axiovert-100 Microscope (Zeiss, German). The magnification of objectives was $20 \mathrm{X}$ and total magnification were $200 \mathrm{X}$. 
sas, VA). Morphology and proliferation rate of hNSCs and MCLts in different media were documented. MCLts grow equally well in coated or uncoated plates, but better with MC growth media (MCmed) than NSC media as expected from the previous figure (Figure $3 \mathrm{~A}$ ). hNSCs, whereas, grow only in gel pre-coated plate (ctd) and with NSC-preferred growth media (NSC med) (Figure 3B).

Morphology further supports these views, as we see (Figure 3C, Figure 3D, Figure 3E and Figure 3F) that hNSCs grow only in gel-coated plate and with NSC med (panel F). Morphology of MCLts was not shown here, but it is same both in gel coated or uncoated plates.

\section{Tolerance with trypsin, a cell harvesting reagent}

Neural stem cells often grow in large clusters that are difficult to dissociate without substantial cell loss, likely from loss of cell-cell contact or disruption of adherent cell processes in this cell population $[25,26]$. Complete dissociation into a single-cell suspension, however, is necessary for accurate cell counts, which can affect the reproducibility of results, assays involving flow cytometry, and studies of the impact of cellcell interactions on survival and maturation of cells both in vitro and in vivo $[27,28]$. Treatment with Accutase, which contains proteolytic and collagenolytic enzymes, Trypsin/EDTA, a serine protease, and Try$\mathrm{pLE}$, a recombinant serine protease, yields dissociat- ed samples. However, there are many other factors that need to be considered, such as the viability of the cell population at post-dissociation.

Here, we showed that hNSCs when harvested with $0.25 \%$ Trypsin, cells do not grow in any media (Figure 4), whereas MCLts show no toxicity with Trypsin (Panel, B). Both the cells, however, can tolerate Accutase, a mild cell-detaching solution (Panel, A.C). hNSCs, as expected, grow better, in NSC-specific media and in gel-coated plate (Panel C) (Figure 4).

\section{Cell-specific protein expression by MCLts and $\mathrm{hN}$ - SCs}

Immunofluorescence study reveals that MCLTs cell express their specific proteins Tyrosinase and TRP-1, whereas hNSCs do not. On the other hand hNSCs, as expected, express Nestin and neuron specific Tuj1 proteins. MCLts do not, however, express either Nestin or Tuj1, as expected (Figure 5A and Figure 5B).

\section{Melanocyte-specific enzyme activity by MCLts and hNSCs}

MCLts, showed the melanogenic proteins, Tyrosinase and Dopachrome Tautomerase (DT/TRP2) activity. These proteins are Melanocyte specific proteins and involved in skin melanin formation, a specialized function of melanocytes. hNSCs do not show any such activity in them (Figure 6).

\section{Tolerance with Accutase and Trypsin}

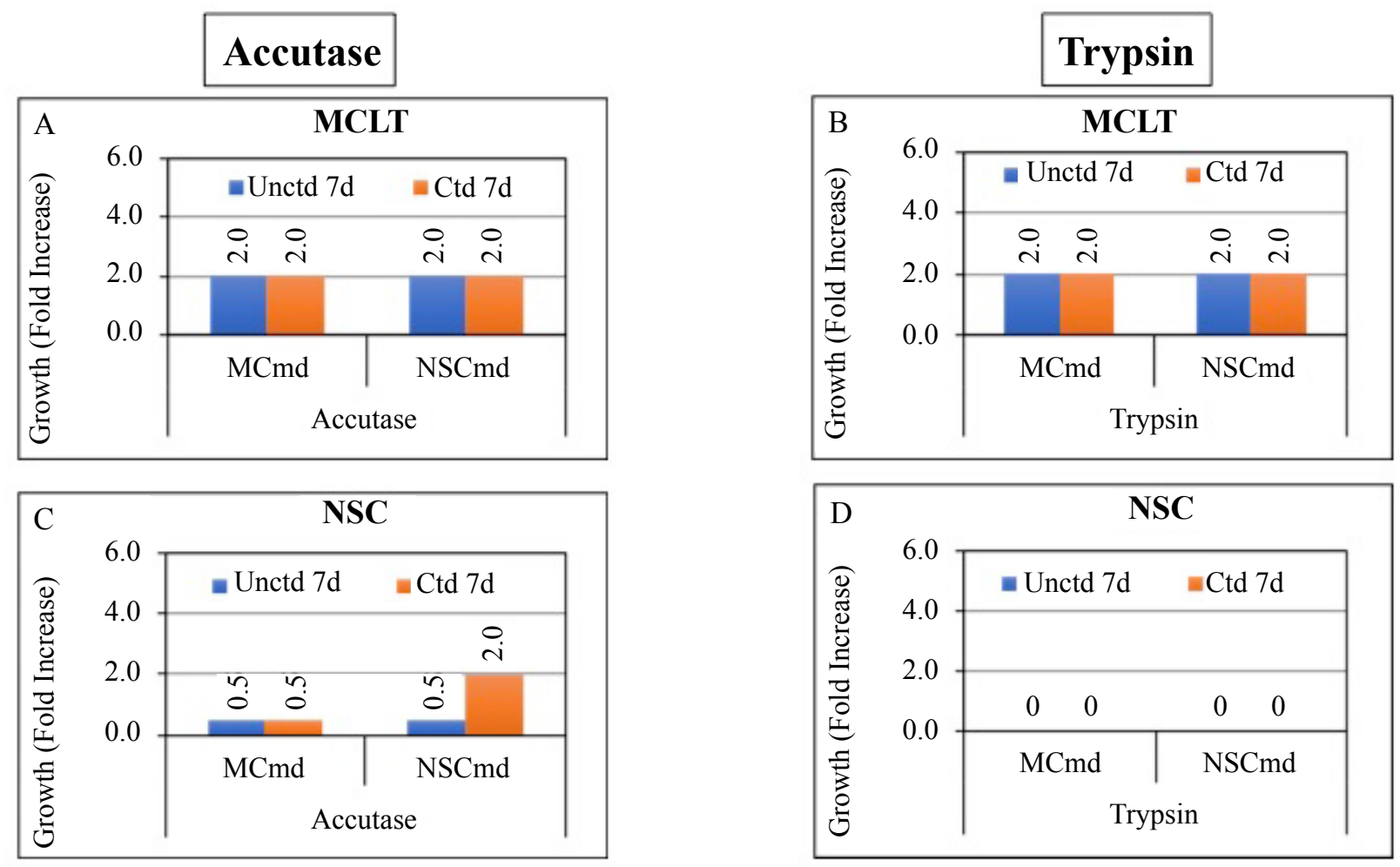

Figure 4: Trypsin is toxic to hNSCs but not to MCLts. hNSCs when harvested with $0.25 \%$ Trypsin, cells doesn't grow in any media (Panel, D), whereas MCLts. doesn't show any toxicity with Trypsin. (Panel, B). Both the cells can tolerates Accutase, a mild cell-detaching solution (Panel, A. C). hNSCs, as expected, grows better however, in NSC-specific media and in coated plate (Panel C). 
A)
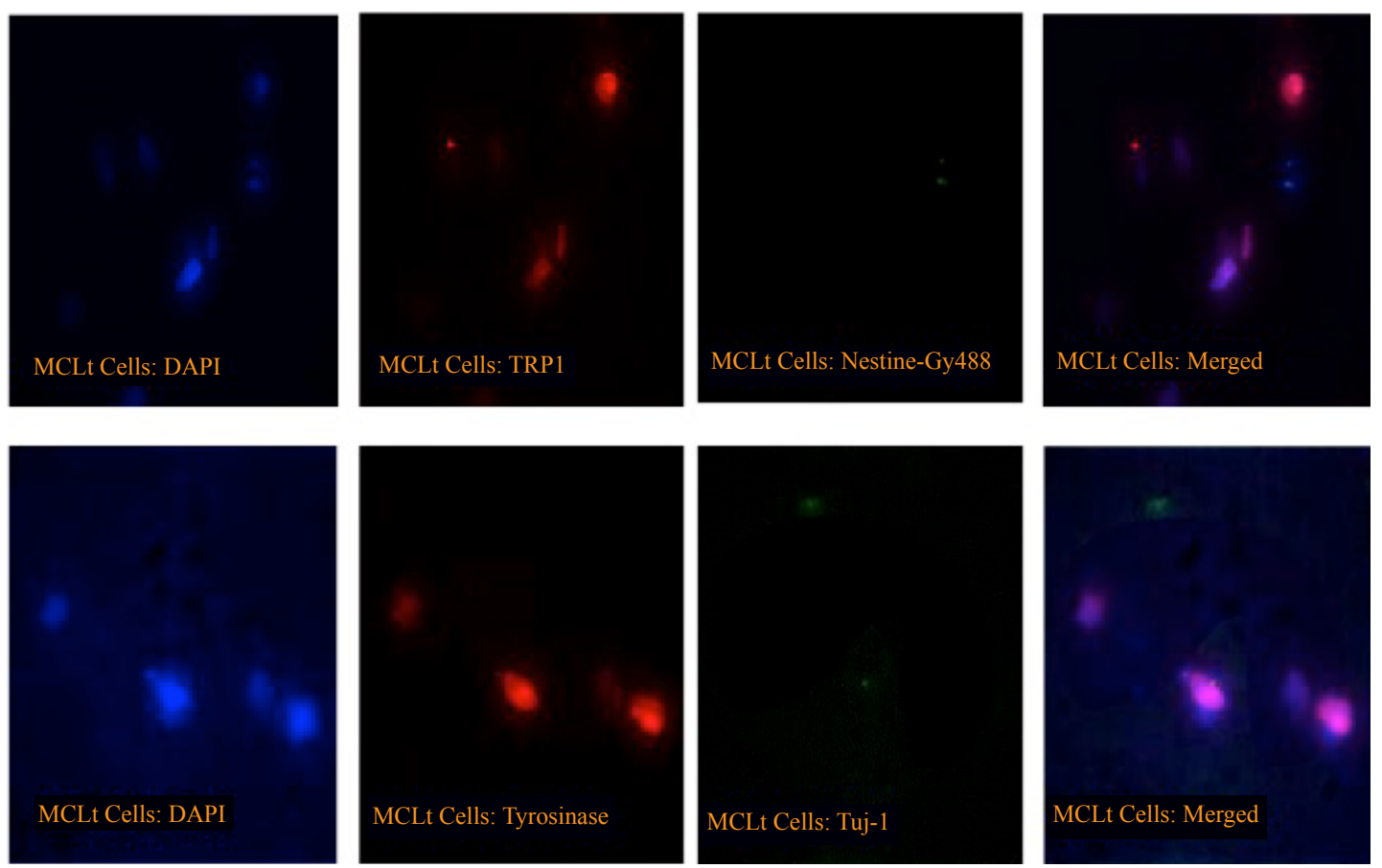

B)
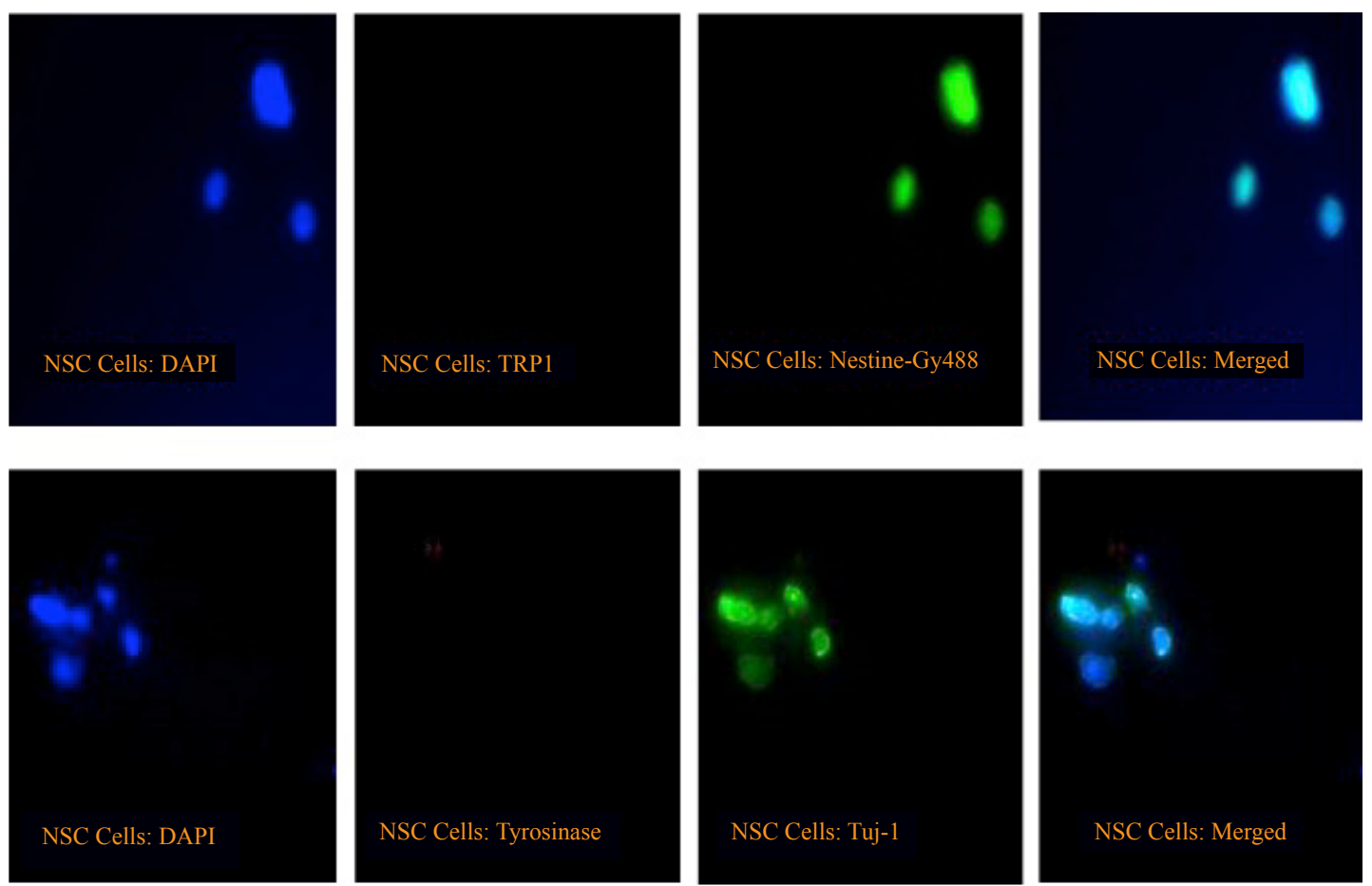

Figure 5: A) MCLt Cells Express Tyrosinase and TRP1 but not Nestin or Tuj1. Immunofluorescence study of MCLt cells were done using some melanocyte-specific antibody as well as NSC-specific antibody as described in the Materials and Method section. Photographs were taken by Axiovert-Fluorescence Microscope (Zeiss, German). The magnification of objectives was 20X and total magnification were 200X. MCLts express only Melanocyte-specific proteins, as expected but not NSC-specific proteins (Nestin, Tuj1); B) hNSC Cells Express Nestin and Tuj but not Tyrosinase or TRP1. Immunofluorescence study of NSCs were done using some melanocyte-specific antibody as well as NSC-specific antibody as described in the Materials and Method section. Photographs were taken by Axiovert-Fluorescence Microscope (Zeiss, German). The magnification of objectives was 20X and total magnification were 200X. hNSCs express only NSC-specific proteins, as expected but not melanocyte-specific proteins (TRP1, Tyrosinase).

\section{NSC-specific enzymatic production and release of dopamine by hNSCs but not by MCLts}

Dopamine (DA) is produced by hNSCs through its Tyrosine Hydroxylase activity on tyrosine. Tyrosine Hydroxylase expression and Dopamine level were measured by using respective ELISA kits as described in the Materials and Methods section. The results were placed from a representative experiment done in triplicate. Values were normalized per cell and expressed as $\mathrm{ng} / 10^{5}$ cells.

hNSCs express TH and produces Dopamine in basal medium and also when induced by DOPA, a substrate of Dopamine. However, MCLts, in either case neither express TH nor produces DA at significant range (Figure 7). 

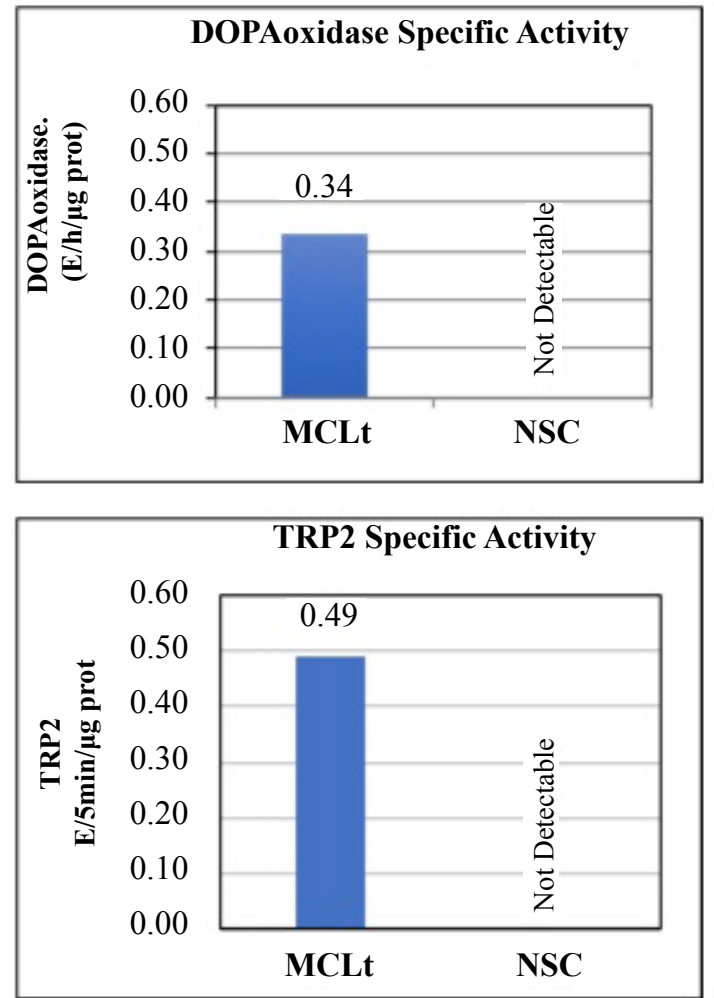

Figure 6: Activity of Melanogenic Proteins (DOPAoxidase/ TRP2). Biochemical analysis of MCLts and hNSCs were done. Dopaoxidase/Tyrosinase and TRP2/Dopachrome tautomerase are two enzymatic activities specific for MCLts, and they do express in them, whereas hNSCs does not. Methods are described in the Materials and Methods section. The data are from a representative experiment done in triplicate. Percentage of error are all within $10 \%$.

\section{Dopamine transporter (DAT) expression and MAO-B activity by hNSCs}

Dopamine transporter (DAT) expression in any Dopamine producing cells is vital in order to maintain a physiological level of Dopamine in the synaptic cleft. Any extra Dopamine should be transported to the cells via DAT and catabolized by MAO-B (Monoamine Oxidase-B enzyme) to DOPAC (3, 4-Dihydroxyphenylacetic acid), before excretion form the body. hNSCs here, as it was shown, have enough DAT expression and MAO-B activity, whereas MCLts show an undetectable range of the both (Figure 8).

\section{DOPAC (3,4-Dihydroxyphenylacetic acid), a me- tabolite of dopamine, assay by HPLC}

DOPAC, a physiological metabolite of Dopamine released in the cell-culture media was measured by HPLC. The specific peak was found only with hNSCs and the amounts were calculated from the peak area using the standard curve. Values were normalized per $10^{5}$ cells and expressed as $\mu \mathrm{g} / \mathrm{mL} / 10^{5}$ cells. DOPAC formation and release in the medium was further increased when its substrate Dopamine was added in the medium (Figure 9).

\section{Discussion}

Parkinson's disease affects around half a million people in the United States, and the number is only expected to rise given the progressive aging of the

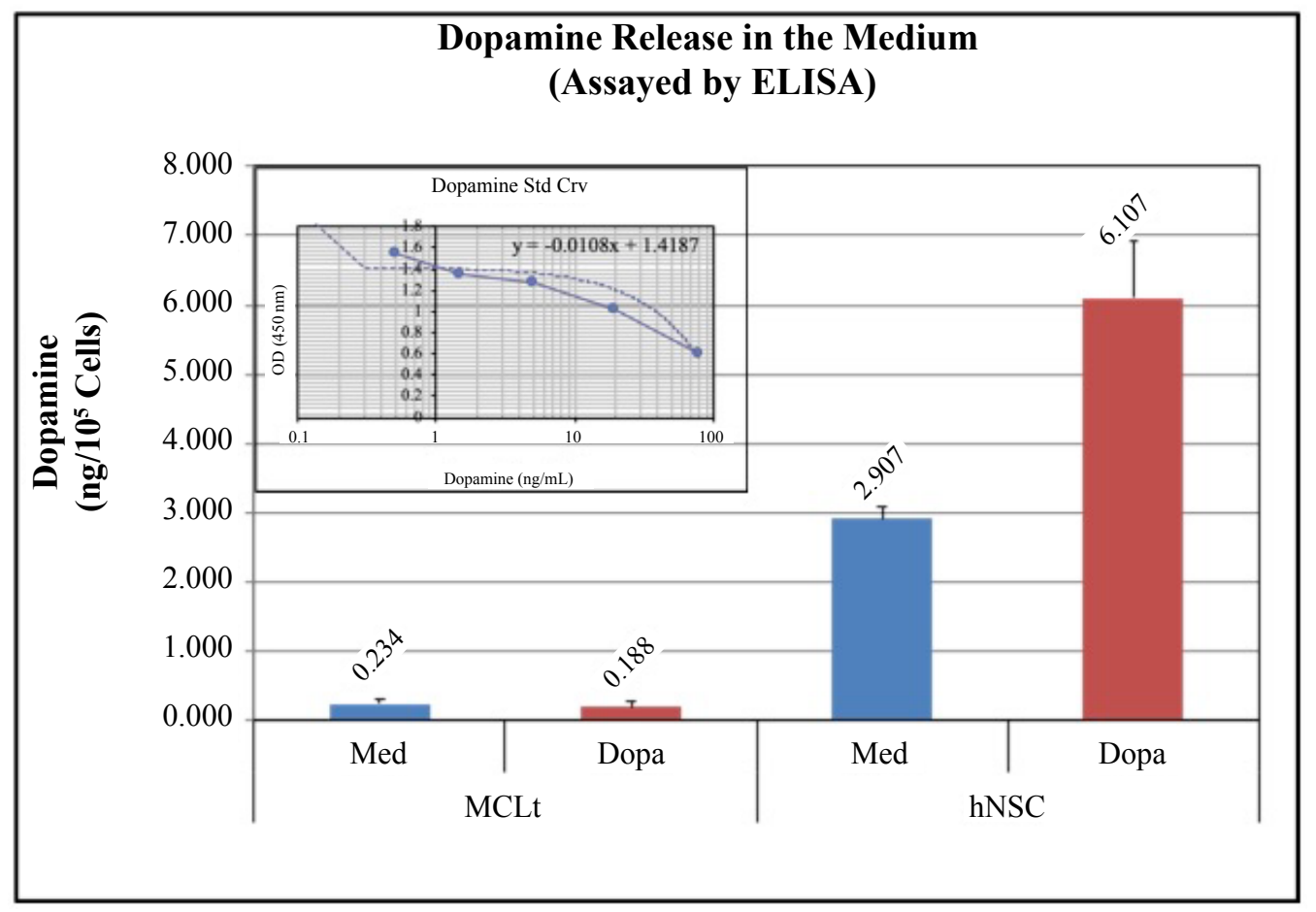

Figure 7: Dopamine (DA) synthesis and Release by hNSCs but not by MCLts. Biochemical analysis of Dopamine release by MCLts and hNSCs were done in triplicate. Unlike MCLts, human neural cells (hNSCs) can synthesize and release Dopamine in the medium. Methods are described in the Materials and Methods section. Values are calculated from the standard Curve (inset) and are normalized per cell and expressed as expressed as ng/10 5 Cells). The data are from a representative experiment done in triplicate. Percentage of error are all within $10 \%$. 

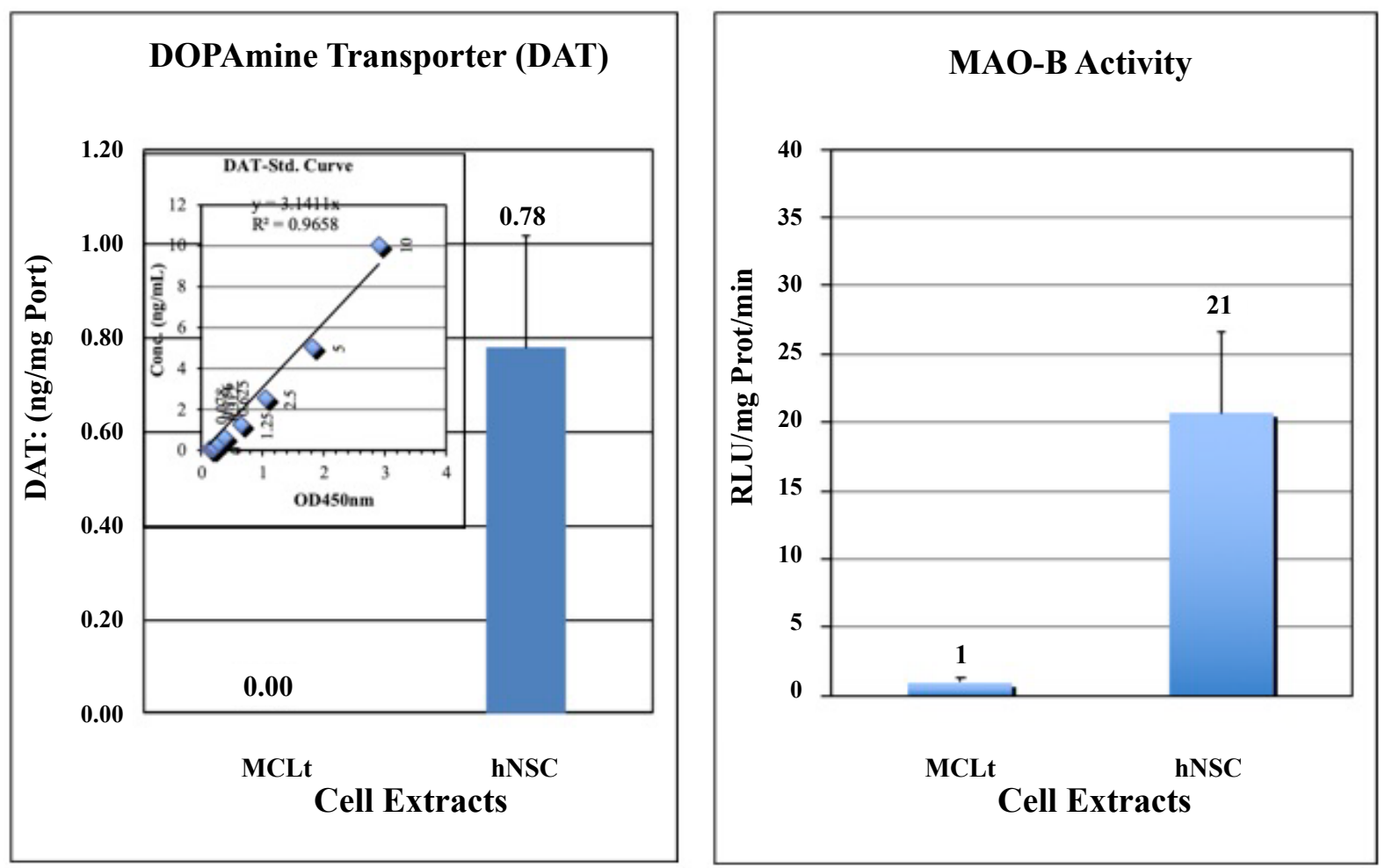

Figure 8: Dopamine Transporter (DAT) and MAO-B Assay by ELISA. Biochemical analysis of Dopamine Transporter (DAT) and MAO-B activity by MCLts and hNSCs were done in triplicate. Unlike MCLts, human neural cells (hNSCs) express DAT and MAO-B activity. These proteins are involved in Dopamine scavenging system to control the Dopamine level in the body. DAT Values are calculated from the standard curve (inset) and are normalized per $\mathrm{mg}$ of Protein, and expressed as $\mathrm{ng} / \mathrm{mg}$ Prot. MAO-B activities are expressed as RLU/mg Prot/min. The data are from a representative experiment done in triplicate. Percentage of error are all within $10 \%$.
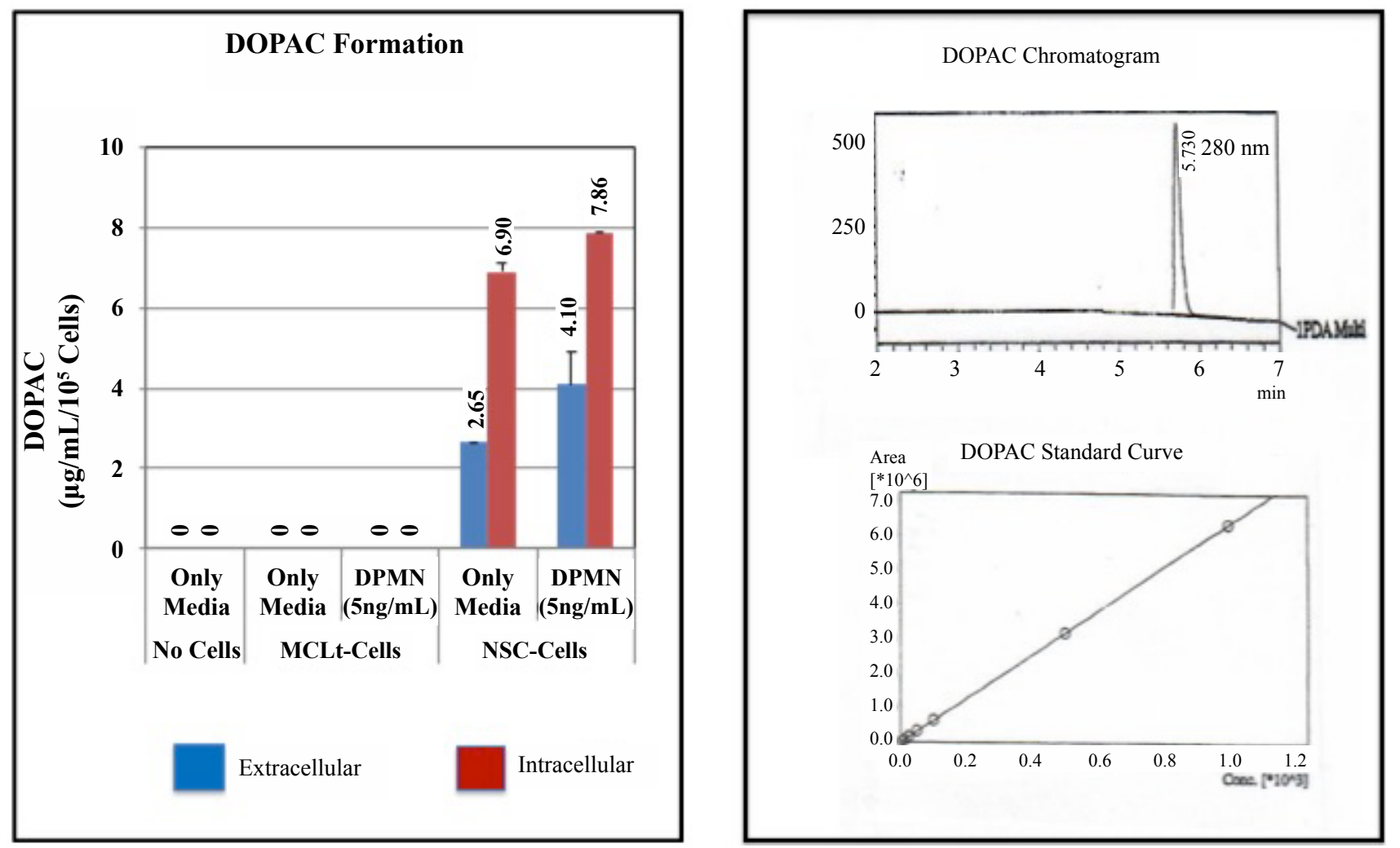

Figure 9: DOPAC Assay by HPLC: Formation of DOPAC by hNSCs. Biochemical analysis of DOPAC formation using HPLC method. hNSCs, but not MCLts, can catabolize Dopamine (DPMN) to DOPAC, as seen by DOPAC Chromatogram. Values were calculated from the DOPAC Standard curve vs. peak area, as described in the Materials and Methods section. Values are normalized per cell and expressed as expressed as $\mathrm{mg} / \mathrm{mL} / 10^{5}$ Cells). The data are from a representative experiment done in triplicate. Percentage of error are all within $10 \%$. 
population [29]. The National Institutes of Health (NIH) estimate that doctors diagnose the condition in around 50,000 people each year (NIH FACT SHEET - Parkinson's Disease, 2010. http://www.ninds.nih. gov). In reality the dopaminergic neurons which is a brain circuit that connects neurons in the substantia nigra pars compacta with the dorsal striatum and situated in the nigrostriatal pathway, are less in number in PD patients [1].

The aetiology are unknown, however many different factors can be counted like, ageing, external assaults, toxicity or may be genetic abnormalities [30].

Currently, the most common therapy uses the drug levodopa, a substrate of dopamine (DA) which is associated with motor skills [31]. Since melanocytes contain Tyrosinase which can synthesize DOPA from Tyrosine, it appears that transplantation of melanocytes can be a better substitute for DOPA therapy than Levodopa administration for PD patients [15]. Levodopa administration to PD patients while a continuous treatment and a palliative, transplantation of melanocytes could be onetime and the cells will supply DOPA regularly as when needed. Neighboring cells, further, can convert DOPA to Dopamine for further downstream signal transduction for muscular movements, and that way a long term cure may be achieved. In fact, supplement of DA synthesis by tyrosinase has been reported in $\mathrm{TH}$ (Tyrosine Hydroxylase) null mice [14]. Further, it was shown earlier by [15] that transplantation of a non-melanogenic cells transfected with tyrosinase gene, as tyrosinase-producing cells, which constitutively produce L-DOPA, resulted in marked amelioration of the asymmetric apomorphine-induced rotation in hemi-parkinsonian mice lesioned with 6-hydroxydopamine (6-OHDA). In an another experiment they have also shown that transplantation of melanocytes from the back skin of black newborn mice, but not from albino mice, showed marked improvement in the apomorphine-induced rotation behavior. Taken together, a therapeutic potential of cell transplantation of melanocytes in patients with Parkinson's disease can be understood.

Another cell type that can be considered to evaluate their potentiality of using as a therapeutic regiment to treat PD patients is human neural stem cells (hNSCs). hNSC contains Tyrosine hydroxylase (TH) that catalyzes the initial, rate-limiting step in the biosynthesis of catecholamines, including DA, noradrenaline, and adrenaline [32]. The most important physiological aspect of functional hNSCs, as we see in our experiments, that they not only have the capability to synthesize DA but also release DA in response to substrate (DOPA)-induced condition than those obtained in control groups. These cells also express DAT (Dopamine Transporter), an another marker for mature and functional DA neurons, plays a key role in terminating dopaminergic signaling by catabolizing any excess DA which is neurotoxic also, to DOPAC, 3,4-Dihydroxy- phenylacetic acid [33].

Now-a-days, stem cells are highly under consideration to be used for cell therapy of various diseases, like Parkinson's Disease, Diabetes, etc. It's applicability and success depend on the right selection of the stem cell type to be used for the purposes, and also the knowledge beforehand regarding the behavior of cells under the different environmental conditions it supposed to work. Generally, stem cell fate, in vitro or in vivo, is associated with intracellular molecular mediators and growth factors (GFs). Many researchers have demonstrated the regulation of stem cells behavior and fate under the influence of different environmental conditions including an ideal cell-extracellular matrix interaction [2]. Further, the stem cells possess a mechanical memory that can control the cells fate, on the base of past physical environments $[5,6]$. Previous studies showed that various chemical, physical, and mechanical signals can be transduced and they can deeply influence the stem cell growth and differentiation, in vivo and in vitro $[34,35]$.

In this context, a growing literature has shown the importance of intracellular mechano-transduction in stem cell differentiation [36]. Recent reports demonstrated that the cells can integrate mechanical signals from the ECM and can transduce them in a directed gene expression $[37,38]$. Thus, ECM and the cell-ECM interactions are important in determining the stem cell fate $[39,40]$. Here we showed that the interaction between human neural stem cells (hNSCs) and ECM, and physical factors of the cell-culture environment were able to influence the distribution, shape and differentiation of hNSCs.

We have here, identified the differences and preferences of growing conditions for MCLts and hNSCs in culture. hNSCs grow only in gel-coated plate and with NSC-specific media, and also they are Trypsin sensitive, whereas MCLts can grow both in gel-coated or uncoated plate and with any media, however NSC specific media is not a preferred one for MCLts. These differences may help the researchers to use for cell selection from aco-culture system, if and when used for cell-cell interaction studies to modify one by the other.

In brief, transplantation of dopaminergic (DA) neurons is considered to be the most promising therapeutic strategy for replacing degenerated dopamine cells in the midbrain of Parkinson's disease (PD), thereby restoring normal neural circuit function and slow clinical progression of the disease. Human neural stem cells (hNSCs) derived from fetal forebrain are thought to be the important cell sources for producing DA neurons because of their multipotency for differentiation and long-term expansion property in cultures. However, the low efficiency to generate functional dopamine neurons from forebrain-derived hNSCs limited their therapeutic potential as the donor cells. 
To confirm whether the differentiated DA neurons from forebrain hNSCs are functional and release dopamine in cultures, the basal and substrate-induced levels of dopamine releases by these cells were respectively assessed with ELISA. As shown in Figure 7, not only the basal levels but also the induced levels of dopamine release were significantly increased compared to those in control groups.

Therefore, hNSCs being equipped with DA production, release, and its breakdown, can efficiently control the physiologic level of DA in the synaptic cleft. Melanocytes (MCLts), though being able to produce DA precursor DOPA, can't be a better choice over NSCs as the melanocytes do not have the DA controlling factors such as DAT and MAO-B. However, hNSCs is a slow growing cell and senesce after a few passages rendering a low level of supply for treatment. Attempts are going to be made to develop a natural cell modification method in our lab to increase the growth potential and survival length of hNSCs by a cell-cell interaction [41-49].

\section{Acknowledgements}

This research is supported by internal grant from All Excel, Inc. Thanks are due to Caresbio, Inc (Westport, CT) for Immunofluorescence study. DOPAC assay by HPLC were done by Dr. Vinod Arora (All Excel, Inc).

\section{References}

1. Alexander GE (2004) Biology of Parkinson's disease: Pathogenesis and pathophysiology of a multisystem neurodegenerative disorder. Dialogues Clin Neurosci 6: 259-280.

2. Suzuki S, Kawamata J, Iwahara N, Matsumura A, Hisahara $S$, et al. (2015) Intravenous mesenchymal stem cell administration exhibits therapeutic effects against 6-hydroxydopamine-induced dopaminergic neurodegeneration and glial activation in rats. Neurosci Lett 584: 276-281.

3. Thanvi B, Lo N, Robinson T (2007) Levodopa-induced dyskinesia in Parkinson's disease: Clinical features, pathogenesis, prevention and treatment. Postgrad Med J 83: 384388.

4. Gaillard A, Jaber M (2011) Rewiring the brain with cell transplantation in Parkinson's disease. Trends Neurosci 34: 124-133.

5. Kirkeby A, Grealish S, Wolf DA, Nelander J, Wood J, et al. (2012) Generation of regionally specified neural progenitors and functional neurons from human embryonic stem cells under defined conditions. Cell Rep 1: 703-714.

6. Yang F, Liu Y, Tu J, Wan J, Zhang J, et al. (2014) Activated astrocytes enhance the dopaminergic differentiation of stem cells and promote brain repair through bFgF. Nat Commun 5: 5627-5640.

7. Lim MS, Shin MS, Lee SY, Minn YK, Hoh JK, et al. (2015) Noggin over-expressing mouse embryonic fibroblasts and ms5 stromal cells enhance directed differentiation of dopaminergic neurons from human embryonic stem cells. PLoS One 10: e0138460.

8. Christophersen NS, Meijer X, Jorgensen JR, Englund U, Gronborg M, et al. (2006) Induction of dopaminergic neurons from growth factor expanded neural stem/progenitor cell cultures derived from human first trimester forebrain. Brain Res Bull 70: 457-466.
9. Knoepfler PS (2009) Deconstructing stem cell tumorigenicity: A roadmap to safe regenerative medicine. Stem Cells 27: 1050-1056.

10. Andersson EK, Irvin DK, Ahlsiö J, Parmar M (2007) Ngn2 and nurr1 act in synergy to induce midbrain dopaminergic neurons from expanded neural stem and progenitor cells. Exp Cell Res 313: 1172-1180.

11. Medvedev SP, Shevchenko AI, Zakian SM (2010) Induced pluripotent stem cells: Problems and advantages when applying them in regenerative medicine. Acta Naturae 2: 1828.

12. Costin GE, Hearing VJ (2007) Human skin pigmentation: Melanocytes modulate skin color in response to stress. FASEB J 21: 976-994.

13. Chen Y, Lian Y, Ma Y, Wu C, Zheng Y, et al. (2017) The expression and significance of tyrosine hydroxylase in the brain tissue of Parkinson's disease rats. Exp Ther Med 14: 4813-4816.

14. Rios M, Habecker B, Sasaoka T, Eisenhofer G, Tian H, et al. (1999) Catecholamine synthesis is mediated by tyrosinase in the absence of tyrosine hydroxylase. J Neurosci 19: 3519-3526

15. Asanuma M, Miyazaki I, Diaz-Corrales F, Higashi Y, Namba M, et al. (2013) Transplantation of melanocytes obtained from the skin ameliorates apomorphine-induced abnormal behavior in rodent hemi-parkinsonian models. PLoS One 8: e65983.

16. Hirobe T (2011) How are proliferation and differentiation of melanocytes regulated? Pigment Cell Melanoma Res 24: $462-478$.

17. Crouch SP, Kozlowski R, Slater KJ, Fletcher J (1993) The use of ATP bioluminescence as a measure of cell proliferation and cytotoxicity. J Immunol Methods 160: 81-88.

18. Oka M, Ichihashi M, Chakraborty AK (1996) Enhanced expression of protein kinase $C$ subspecies during stimulation of melanogenesis in B16 mouse melanoma cells. J Invest Dermatol 106: 377-378.

19. Orlow SJ, Osber MP, Pawelek JM (1992) Synthesis and characterization of melanins from dihydroxyindole-2- carboxylic acid and dihydroxyindole. Pigment Cell Res 5: 113121.

20. Chakraborty AK, Platt J, Kim KK, Kwon BS, Bennett DC, et al. (1996) Polymerization of 5,6-dihydroq4ndole-2-carboxylic acid to melanin by the pmell7/silver locus protein. Eur $\mathrm{J}$ Biochem 236: 180-188.

21. Korner AM, Pawelek JM (1980) Dopachrome conversion: A possible control point in melanin biosynthesis. Jlnvest Dermatol 75: 192-195.

22. Fauss D, Motter R, Dofiles L, Armanda M, Rodrigues $V$, et al. (2013) Development of an enzyme-linked immunosorbent assay (ELISA) to measure the level of tyrosine hydroxylase protein in brain tissue from Parkinson's disease models. J Neurosci Methods 215: 245-257.

23. Valley M, Zhou W, Hawkins EM, Shultz J, Cali JJ, et al. (2006) A bioluminescent assay for monoamino oxidase activity. Anal Biochem 359: 238-246.

24. De Benedetto GE, Fico D, Pennetta A, Malitesta C, Nicolardi $G$, et al. (2014) A rapid and simple method for the determination of 3,4-dihydroxyphenylacetic acid, norepinephrine, dopamine, and serotonin in mouse brain homogenate by HPLC with fluorimetric detection. J Pharm Biomed Anal 98: $266-270$. 
25. Ohnuma K, Fujiki A, Yanagihara K, Tachikawa S, Hayashi $Y$, et al. (2014) Enzyme-free passage of human pluripotent stem cells by controlling divalent cations. Sci Rep 4: 4646.

26. Svendsen $\mathrm{CN}$, ter Borg MG, Armstrong RJ, Rosser AE, Chandran S, et al. (1998) A new method for the rapid and long term growth of human neural precursor cells. J Neurosci Methods 85: 141-152.

27. Panchision DM, Chen HL, Pistollato F, Papini D, Ni HT, et al. (2007) Optimized flow cytometric analysis of central nervous system tissue reveals novel functional relationships among cells expressing CD133, CD15, and CD24. Stem Cells 25: 1560-1570.

28. Lin CH, Lee DC, Chang HC, Chiu IM, Hsu CH (2013) Single-cell enzyme-free dissociation of neurospheres using a microfluidic chip. Anal Chem 85: 11920-11928.

29. Marras C, Beck JC, Bower JH, Roberts E, Ritz B, et al. (2018) Prevalence of Parkinson's disease across North America. Npj Parkinson's Disease 4: 1-7.

30. Inamdar NN, Arulmozhi DK, Tandon A, Bodhankar SL (2007) Parkinson's disease: Genetics and beyond. Curr Neuropharmacol 5: 99-113.

31. Haddad F, Sawalha M, Khawaja Y, Najjar A, Karaman R (2018) Dopamine and levodopa prodrugs for the treatment of parkinson's disease. Molecules 23: 1-17.

32. Colette Daubner S, Le T, Wang S (2011) Tyrosine hydroxylase and regulation of dopamine synthesis. Arch Biochem Biophys 508: 1-12.

33. German CL, Baladi MG, McFadden LM, Hanson GR, Fleckenstein AE (2015) Regulation of the dopamine and vesicular monoamine transporters: Pharmacological targets and implications for disease. Pharmacol Rev 67: 10051024.

34. Kshitiza KM, Park J, Kima P, Helen W, Engler AJ, et al. (2012) Control of stem cell fate and function by engineering physical microenvironments. Integr Biol (Camb) 4: 10081018.

35. Gattazzo F, Urciuolo A, Bonaldo P (2014) Extracellular matrix: A dynamic microenvironment for stem cell niche. Biochim Biophys Acta 1840: 2506-2519.

36. Wang N (2017) Review of cellular mechano transduction. J Phys D Appl Phys 50: 1-14.

37. Donald E Ingber (2002) Mechanical signaling and the cel- lular response to extracellular matrix in angiogenesis and cardiovascular physiology. Circ Res 91: 877-887.

38. Sarasa-Renedo A, Chiquet M (2005) Mechanical signals regulating extracellular matrix gene expression in fibroblasts. Scand J Med Sci Sports 15: 223-230.

39. Ahmed M, Ffrench-Constant C (2016) Extracellular matrix regulation of stem cell behavior. Curr Stem Cell Rep 2: 197206.

40. Farshid G, Cohen DM, Estes BT, Gimble JM, Liedtke W, et al. (2009) Control of stem cell fate by physical interactions with the extracellular matrix. Cell Stem Cell 5: 17-26.

41. Asanuma M, Miyazaki I, Ogawa N (2003) Dopamine or L-DOPA-induced neurotoxicity: The role of dopamine quinone formation and tyrosinase in a model of Parkinson's disease. Neurotox Res 5: 165-176.

42. Halder G, Dupont S, Piccolo S (2012) Transduction of mechanical and cytoskeletal cues by YAP and TAZ. Nat Rev Mol Cell Biol 13: 591-600.

43. Hasegawa T (2010) Tyrosinase-expressing neuronal cell line as in vitro model of parkinson's disease. Int $\mathrm{J}$ Mol Sci 11: $1082-1089$.

44. Jha AK, Jackson WM, Healy KE (2014) Controlling osteogenic stem cell differentiation via soft bioinspired hydrogels. PLoS One 9: e98640.

45. Kuhn DM, Arthur RE Jr, Thomas DM, Elferink LA (1999) Tyrosine hydroxylase is inactivated by catechol-quinones and converted to a redox-cycling quinoprotein: Possible relevance to parkinson's disease. J Neurochem 73: 1309-1317.

46. Miranda M, Botti D, Bonfigli A, Ventura T, Arcadi A (1984) Tyrosinase-like activity in normal human substantia nogra. General Pharmacology 15: 541-544.

47. Segklia A, Seuntjen E, Elkouris M, Tsalavos S, Stappers $\mathrm{E}$, et al. (2012) Bmp 7 regulates the survival, proliferation, and neurogenic properties of neural progenitor cells during corticogenesis in the mouse. PLoS One 7:e34088.

48. Tief K, Schmidt A, Beermann F (1998) New evidence for presence of tyrosinase in substantia nigra, forebrain and midbrain. Brain Res Mol Brain Res 53: 307-310.

49. Yang H, Wang J, Wang F, Liu X, Chen H, et al. (2016) Dopaminergic neuronal differentiation from the forebrain-derived human neural stem cells induced in cultures by using a combination of bmp-7 and pramipexole with growth factors. Front Neural Circuits 10: 29-34. 